\title{
Erratum to: Osteoconduction capacity of human deciduous and permanent teeth ash in a rat calvarial bone defect model
}

\author{
Boram Min • Je Seon Song • Seong-Oh Kim • \\ Kwang-Mahn Kim • Won Se Park · Jae-Ho Lee
}

Published online: 28 April 2015

(C) Springer Science+Business Media Dordrecht 2015

\section{Erratum to: Cell Tissue Bank DOI 10.1007/s10561-014-9480-7}

Unfortunately, in the original publication of the article, the funding information in the acknowledgment section was incorrectly published. The correct information should read as below

Acknowledgments This study was supported by a faculty research Grant of Yonsei University College of Dentistry for 2013(6-2013-0117)

The online version of the original article can be found under doi:10.1007/s10561-014-9480-7.

B. Min · J. S. Song $\cdot$ S.-O. Kim · J.-H. Lee $(\bowtie)$

Department of Pediatric Dentistry, College of Dentistry,

Yonsei University, 250 Seongsanno,

Seodaemun-gu, Seoul 120-752, Korea

e-mail: jsmsr@naver.com; leejh@yuhs.ac

B. Min · J. S. Song $\cdot$ S.-O. Kim $\cdot$ J.-H. Lee

Oral Science Research Center, College of Dentistry,

Yonsei University, Seoul, Korea

K.-M. Kim

Department of Dental Biomaterials and Bioengineering,

College of Dentistry, Yonsei University, Seoul, Korea

W. S. Park

Department of Advanced General Dentistry, College of

Dentistry, Yonsei University, Seoul, Korea 